EESTI NSV TEADUSTE AKADEEMIA TOIMETISED. 21. KÖIDË

KEEMIA * GEOLOOGIA. 1972, NR. 2

ИЗВЕСТИЯ АКАДЕМИИ НАУК ЭСТОНСКОИ ССР. ТОМ 21

ХИмИЯ * ГЕОЛОГИя. 1972, № 2

\title{
СОСТАВ И КОЛИЧЕСТВО ДЕТРИТА В ОТЛОЖЕНИЯХ ОСЕВОЙ ФАЦИАЛЬНОЙ ЗОНЫ ОРДОВИКА ПРИБАЛТИКИ
}

\author{
(ПО СКВАЖИНЕ ЭНГУРЕ)
}

С начала 50-х годов в литологии карбонатных отложений намечается все более увеличивающаяся тенденция $\mathrm{K}$ детальному изучению количественных и качественных характеристик детрита. Первыми применяли точные количественные методы предсгавители французско-итальянской школы А. Кароцци (см. Carozzi, 1958), Ж. Кювийе (см. Sadler, 1966) и другие. Количественные методы получили в дальнейшем очень широкоа применение во многих сгранах (Stauffer, 1962; Cronoble and Waddell, 1966; Lindholm, 1969 и др.). В Советском Союзе на необходимость всестороннего изучения детрита было обращено внимание В. Масловым (1937), М. Швецсвым (1958), И. Хворовой (1958) и многими другими. Это вполне есгественно, учитывая, что детрит играет существенную (часто основную) роль при формировании карбонатных толщ как древних, так и современных бассейнов. Изучение характеристик детрита необходимо при детальных литологических, палеоэкологических, палеогеографических, фациальных, а также стратиграфических исследованиях.

По отложениям Балтийского ордовикского бассейна первые детальные данные о распространении детрита и его групповом сюставе приведены В. Яануссоном (Јaanusson, 1952) и Ю. Мартна (Martna, 1955). В. Яануссон усовершенствовал методику количественного определения детрита для ордовикских карбонатных пород и обосновал границы гранулометрических групп органогенно-обломочного компонента. Ю. Мартна, помимо гранулометрического состава дегрита, впервые исследовал групповой состав органогенно-обломочного материала пограничных слоев среднего и верхнего ордовика Швеции.

В Прибалтике проблемы детального количественного изучения карбонатных пород (в том числе и детрита) стали более актуальными после работы Р. Мянниля (1966) о развитии Балтийского бассейна в ордовике, в которой приведено также фациальное расчленение его отложений, принятое и в настоящей статье.

В последние годы в северной фациальной зоне эстонскими геологами проведено несколько более детальных исследований детрига, результаты которых частично уже опубликованы (Вингисаар, 1971).

Нами предпрннята попытка охарактеризовать содержание и групповой состав детрита в сравннтельно пслном терригенно-карбонатном разрезе ордовика из осевой фащиальной зоны. Объектом исследозания был выбран керн скв. Энгуре Латвийской ССР (рнс. 1), возможность описания и опробования котороге любезно предоставлена Управ. лением геологии СМ Латвийской ССР.

Детальное макролитологическое описание керна составлено автором вместе с Р. Эйнасто в 1965 г. Химическне анализы выпольены в лаборатории Института геологии АН ЭССР Л. Сяга и И. Лыоке. Стратиграфическое расчленение разреза дано по материалам Р. Мянннля и Л. Хинтс (см. Мянниль и др., 1968). Многие ценные методические указания получены от доктора В. Яануссона (Стокгольм). Автор приносит искреннюю благодарность всем названным выше лицам. 
Для лабораторной обработки было отобрано 135 проб. Все выделенные литокомплексы (интервалы описания керна) в зависимости от их мощности представлены одним или несколькими образцами. Интервал опробования в среднем составлял 1,2 м. Для большей представительности шлифов и проб, предназначенных на химические анализы, они выбирались на предварительно распиленных ровных поверхностях образцов.

Было изготовлено 148 шлифов, из которых 106 содержали органические остатки в виде детрита (размеры обломков более 0,1 мм) и шлама (размеры обломков менее 0,1 м. $)$. В детрите присутствовали остатки следующих основных групп организмов: трилобитов, остракод, иглокожих, брахиопод, мшанок и водорослей. В связи с минимальной перекристаллизацией пород нет необходимости выделять раздел неопределяемых остатков, редкое их появление отнесено к группе varia. Кроме неопределимого детрита, в эту группу отнесены спорадически встречающиеся обломки гастропод, наутилоидей, двустворок,

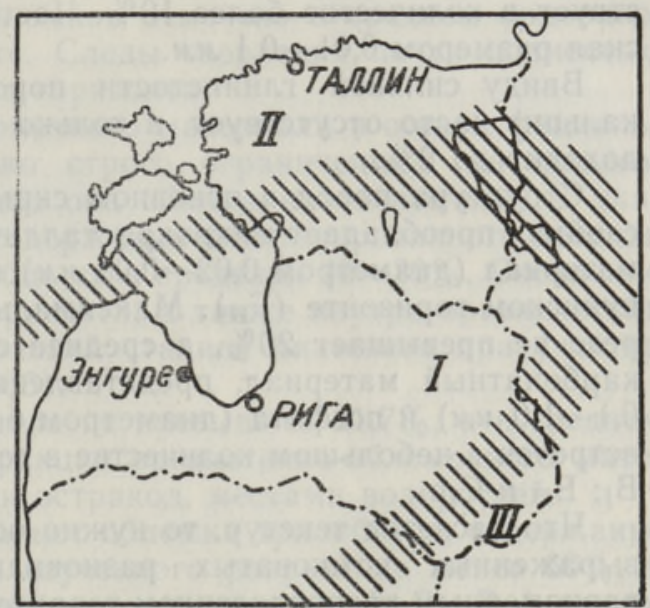

Рис. 1. Фациальная схема ордовика Северной и Средней Прибалтики. Фациальные зоны: I - осевая, II - северная, III - южная. Штриховкой показана переходная полоса между фациальными зонами. ругоз и граптолитов.

Для получения объемных процентов детрита и шлама, а также группового состава детрита был использован метод подсчета точек, предложенный А. Глаголевым (1933) для минералогического анализа, но в последнее время широко применяемый и при изучении карбонатных пород (см. Purdy, 1963). Әтот метод менее трудоемок, чем методы М. Делесса и А. Розивала, и обеспечивает в общем ту же точность (см. Глаголев, 1933). Количество точек подсчета для каждого шлифа выбиралось не менее 500 .

Результаты 110 химических анализов при пересчете на минеральные компоненты в весовых процентах приведены на рис. 2, слева от литологической колонки.

\section{Общая литологическая характеристика разреза}

Терригенно-карбонатные отложения ордовика пройдены скважиной Энгуре в интервале * $867,30-1041,30$ м $\left(\mathrm{A}_{\mathrm{III}}\right.$ ?- $\left.\mathrm{F}_{1 \mathrm{II}}\right)$. Они залегают на размытой поверхности песчаников и алевролитов пакерортского горизонта $\left(\mathrm{A}_{\text {II }}\right)$ ордовика и перекрываются терригенно-карбонатными породами юуруского горизонта $\left(\mathrm{G}_{\mathrm{I}-\mathrm{II}}\right)$ силура.

Согласно результатам анализов данный разрез характеризуется значительной глинистостью пород, свойственной всей осевой фациальной зоне Прибалтики. Среднее содержание терригенного материала в породах по 126 анализам составляет $39,7 \%$. К чистым известнякам на основе принятой нами классификации (Вингисаар и др., 1965) можно отнести только 1,8\% всех анализированных проб. В разрезе преобладают глини-

* При определении глубнн данные каротажа не учитывались. 
стые известняки и известковые мергели при значительном участии в некоторых интервалах $\left(\mathrm{B}_{\mathrm{I}} ; \mathrm{D}_{\mathrm{II}} ; \mathrm{F}_{\mathrm{I}} \mathrm{cJ}\right)$ глинистых мергелей и известковых глин.

Количество доломита в породе в подавляющей части разреза незначительно - в среднем $5,1 \%$. Только в нижней части нижнего ордовика $\left(\mathrm{A}_{\text {III }}\right.$; низы $\left.\mathrm{B}_{\mathrm{I}}\right)$ и в верхнем ордовике $\left(\mathrm{F}_{\mathrm{II}}\right.$; верхи $\left.\mathrm{F}_{\mathrm{I}} \mathrm{cJ}\right)$ доломит присутствует в количестве более $10 \%$. Часто форма кристаллов ромбоэдрическая размером $0,01-0,1$ мм.

Ввиду сильной глинистости пород вторичный заполняющий поры кальцит часто отсутствует и только в редких случаях количество его доходит до $2 \%$.

Структура пород в основном скрытокристаллическая, в редких прослойках преобладает микрскристаллическая основная масса. Сгустковый материал (диаметром 0,02-0,08 мм) встречен практически только в поркуниском горизонте $\left(\mathrm{F}_{\mathrm{II}}\right)$. Максимальное его содержание в данном разрезе не превышает $20 \%$, а среднее составляет около $5 \%$. Обломочный карбонатный материал, представленный в виде псаммита (диаметром $0,1-1,0$ м.м ) и псефита (диаметром более 1,0 мм), в разрезе скв. Энгуре встречен в небольшом количестве в горизонте $F_{\text {II }}$ и нзредка в горизонтах $\mathrm{B}_{\mathrm{I}} ; \mathrm{B}_{\mathrm{II}}$ и $\mathrm{C}_{\mathrm{I}} \mathrm{b}$.

Что касается текстур, то нужно особенно подчеркнуть редкость ясно выраженных комковатых разновидностей, вероятно, обусловленную равномерным распределением терригенного материала в осадке. Количество более или менее ясно выраженных поверхностей перерыва не превышает 30. Асимметричные знаки ряби описаны только из поркуниского горизонта. Трещины усыхания, кроме поркуниского горизонта, встречены в азериском горизонте $\left(\mathrm{C}_{\mathrm{I}} \mathrm{a}\right)$.

\section{Характеристика детрита}

Результаты исследования детрита приведены на рис. 2, справа от литологической колонки.

Среднее содержание детрита по данным 106 шлифов составляет $11,4 \%$. Максимальное содержание его в изученном разрезе доходит до $64,2 \%$ (прослойка мощностью 5 cм в средней части пиргуского горизонта, $\left.\mathrm{F}_{\mathrm{I}} \mathrm{cJ}\right)$. Только в 11 шлифах содержание детрита превышает $20 \%$. Относительно высоким постоянным содержаннем детрита выделяются кукрузеский горизонт $\left(\mathrm{C}_{\mathrm{II}}\right)$ и прослои в пилтенской пачке поркуниского горизонта (см. Волколаков, Спрингис, 1969), отсутствующей в данном разрезе.

Детрит преимущественно мелкий. Содержание крупного детрита (размеры обломков более 1 м.м) в среднем около $10 \%$ и не превышает $50 \%$. Крупный детрит чаще встречается в кукрузеском и поркуниском горизонтах.

В подавляющем большинстве детрит неокатанный. Слаб̆ая окатанность главным образом крупного детрита встречена в кукрузеском горизонте. Хорошо окатанный детрит характерен только для верхов $\mathrm{F}_{\text {II. }}$

Распределение детрита в изучаемом разрезе как по количеству, так и го групповому составу довольно равномерное. Тенденция к концентрации в виде скоплений наблюдается преимущественно в средней части среднего ордовика (в основном $\mathrm{C}_{\text {II }}$ ). Послойная концентрация детрита прослеживается местами в верхнем ордовике, в частности в пределах $F_{\text {II. }}$

Ориентация детрита в преобладающей части разреза беспорядочная. Только при послойной концентрации выделяется строгая горизонтальная упаковка органогенно-обломочного материала.

При характеристике детрита нельзя не отметить широкое распростра- 
нение в скелетных остатках следов жизнедеятельности дезинтегрирующих организмов (по-вндимому, сверлящие водоросли, см. Маслов, 1956) в виде извилистых и иногда разветвляющихся ходов (диаметром 0,03-0,04 мм). Ориентировочно, среднее содержание детрита со следами сверления около $20 \%$, а максимальное доходит до $50 \%$. Ходы сверления обнаружены в скелетных остатках практически всех групп фауны. Наибольшее количество таких обломков отмечено в среднем ордовике, особенно в кукрузеском горизонте. Следы сверления почти полностью отсутствуют в верхах поркуниского горизонта.

Пиритизация органогенно-обломочного материала в осевой фациальной зоне связана с относительно строго ограниченным интервалом $\mathrm{C}_{\text {II }}-\mathrm{D}_{\text {II }}$, в остальной части разреза она обычно незначительна. В указанном интервале максимальное содержание пиритизированного детрита доходит до $80 \%$, а в среднем колеблется в пределах $20-30 \%$. Скопление мелкорассеянного пирита на поверхности, а также внутри органических остатков обычно связывается с ранней стадией диагенеза при участии анаэробных бактерий (Sugden, 1966).

Количество шламового материала не превышает $21,7 \%$, а в среднем составляет лишь $6,7 \%$. В этой фракции органогенно-обломочного материала часто преобладают обломки остракод, местами водорослей.

Ведущее место в детрите занимают обломки трилобитов, содержание которых в преобладающей части изученного разреза не менее $60 \%$, в среднем $76 \%$. В нижней части нижнего ордовика $\left(\mathrm{A}_{I I}\right.$ ?; $\left.\mathrm{B}_{\mathrm{I}} ; \mathrm{B}_{\mathrm{II}}\right)$ трилобиты часто служат почти единственной детритообразуюшей группой организмов. Лишь в верхах ордовика (особенно $\mathrm{F}_{\text {II }}$ ) отмечено общее уменьшение трилобитового материала.

Детрит иглокожих распространен практически по всему изученному интервалу. Среднее содержание этой группы составляет 14,5\%. Максимум $(61,2 \%)$ остатков иглокожих зафиксирован в блиденской пачке оандуского горизонта $\left(\mathrm{D}_{\mathrm{III}} \mathrm{B}\right)$.

Остракодовый детрит присутствует почти во всех изученных шлифах. Среднее его содержание 5-7\%, максимальное доходит до $22,2 \%$ (F $\left.{ }_{\mathrm{I}} \mathrm{CJ}\right)$. Бӧльшие количества детрита остракод приурочены к верхам среднего и низам верхнего ордовика.

Скелетные остатки замковых брахиопод более или менее постояннс встречаются начиная с верхней половины ухакуского горизонта, ниже отмечены главным образом редкие обломки беззамковых. Среднее содержание брахиоподового детрита 5-6\%. Бо́льшим содержанием последнего выделяются горизонты $F_{I} \mathrm{cJ}, \mathrm{F}_{\Pi}$ и $\mathrm{D}_{\mathrm{II}} \mathrm{B}$, причем в $\mathrm{D}_{I I} \mathrm{~B}$ наблюдается максимум - $16,7 \%$.

Остатки водорослей в данном разрезе, как и везде в осевой фациальной зоне ордовика, довольно скудные и с трудом определяемые даже на групповом уровне. Только в верхнем ордовике встречены сравнительно хорошо определимые остагки родов Solenopora и Girvanella. Водорослевый детрит прежде всего приурочен к трем интервалам - $\mathrm{B}_{\mathrm{II}}-\mathrm{C}_{\mathrm{I}} \mathrm{b}$, $\mathrm{C}_{\mathrm{II}}-\mathrm{D}_{\mathrm{III}}$ и верхней половине $\mathrm{F}_{\mathrm{II}}$. Среднее содержание их около $5 \%$, a максимальное достигает 20,8\%. В остальной части разреза водоросли практически отсутствуют.

Детрит мшанок очень редкий. Первые единичные обломки встречены в породах ласнамягиского горизонта $\left(\mathrm{C}_{\mathrm{I}} \mathrm{b}\right)$, но более чем $10 \%$-ное содержание их отмечено лишь в верхней части поркуниского горизонта (максимум $83,5 \%$ ).

Группа varia присутствует в количестве около $5 \%$, в редких случаях доходя до $18 \%$. В подавляющей части разреза она отсутствует полностью, 


\section{Выводы}

Многими исследователями (Мянниль, 1966; Шварц и Карпицкий, 1970 , и др.) подчеркивается значительная выдержанность вещественного состава, структур и текстур ордовикских терригенно-карбонатных пород в пределах всей осевой фациальной зоны Прибалтики. Әто подтверждается и литологическим изучением нами около 20 скважин из разных частей данного региона. Сказанное позволяет распространить результаты, полученные при детальном микролитологическом изучении ордовикского разреза скв. Энгуре, на бо́льшую часть территории осевой фациальной зоны или, по крайней мере, на ее центральную часть.

В осевой фациальной зоне ордовика Прибалтики преобладают илистые и зернисто-илистые отложения. Содержание зернистого компонента, главным образом детрита, только в редких случаях превышает $25 \%$. Детрит в основном неотсортированный, неориентированный, неокатанный. При формировании его значительную роль играл, по-видимому, биологический фактор (обилие в детрите следов жизнедеятельности сверлящих водорослей). У многих групп фауны (особенно остракод, брахиопод и мшанок) прослеживается сравнительно тонкий скелет.

В преобладающей части разрез монодетритовый, среднее содержание обломков трилобитов $76 \%$. На втором месте - остатки иглокожих со средним содержанием около $15 \%$. Количество детрита таких групп как остракоды, брахиоподы, водоросли, мшанки в среднем не превышает $5 \%$. Очень редки находки обломков гастропод, наутилоидей, двустворчатых моллюсков и ругоз. Отсутствуют обломки колониальных кораллов.

Между изученными группами органогенно-обломочного материала существует ряд довольно ясно выраженных зависимостей. В ряде горизонтов (особенно в $\mathrm{B}_{\mathrm{II}} ; \mathrm{C}_{\mathrm{I}} \mathrm{c} ; \mathrm{D}_{\mathrm{III}} \mathrm{B} ; \mathrm{F}_{\mathrm{I}} \mathrm{CJ}$ ) прослеживается обратно про. порциональная зависимость между количеством детрита трилобитов и иглокожих, хорошо демонстрирующая направленность осадконакопле ния. О взаимной зависимости содержаний других групп детрита трудно судить ввиду их немногочисленности и зачасгую полного исчезновения. Пропорциональная зависимость существует между шламом и детритом, а также между общим количеством детрита и содержанием водорослей. Изменения в количестве терригенной примеси, а также красноцветность пород не зависят от группового состава и количества детрита.

Осадконакопление в этой части бассейна было сравнительно непрерывным (редкость поверхностей перерыва), но временами сильно некомпенсированным (черные граптолитовые аргиллиты - $\mathrm{D}_{\mathrm{II}} \mathrm{M}, \mathrm{F}_{\mathrm{I}} \mathrm{b}$; частично мергели и глины - $\left.\mathrm{D}_{\mathrm{III}} \mathrm{B}\right)$.

Количество доломита ничтожное, в подавляющей части разреза он, по-видимому, раннедиагенетический. Нсточником магния был, вероятно, высокомагнезиальный кальцит, присутствовавший в скелетных остатках организмов. Повышенное содержание доломита в начале $\left(\mathrm{A}_{\mathrm{III}}\right.$ ? и низы $\left.\mathrm{B}_{\mathrm{I}}\right)$ и конце $\left(\mathrm{F}_{\mathrm{II}}\right)$ ордовика связано с относительно прибрежными условиями седиментации, вероятно, более благоприятными для накопления высокомагнезиального кальцита в виде остатков водорослей. Не исключено, что в раннем ордовике концентрации магния в осадках содействовала способность глауконита к реакциям катионного обмена (Kahle, 1965).

На основе изложенного выще можно заключить, что в ордовике в пределах преобладающей части осевой фациальной зоны Прибалтики господствовали относительно открытоморские и глубоководные условия со слабой гидродинамической активностью. На этом общем фоне четко выделяется ряд более или менее продолжительных этапов, на которых накопление осадков характеризуется бо́льшим содержанием зернистого 


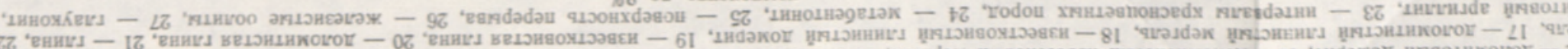

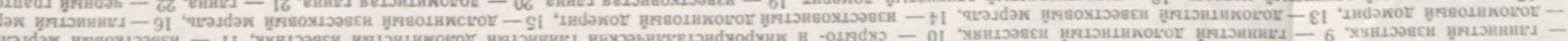

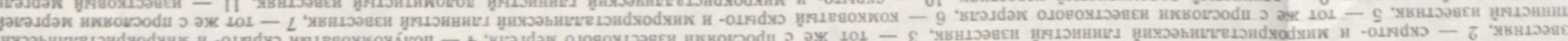

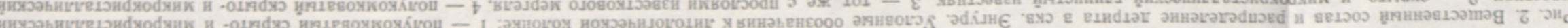

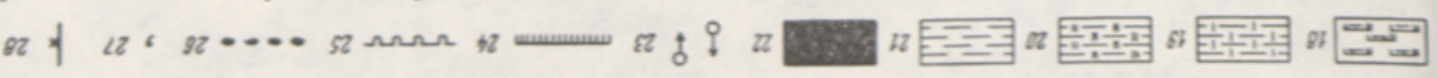

a

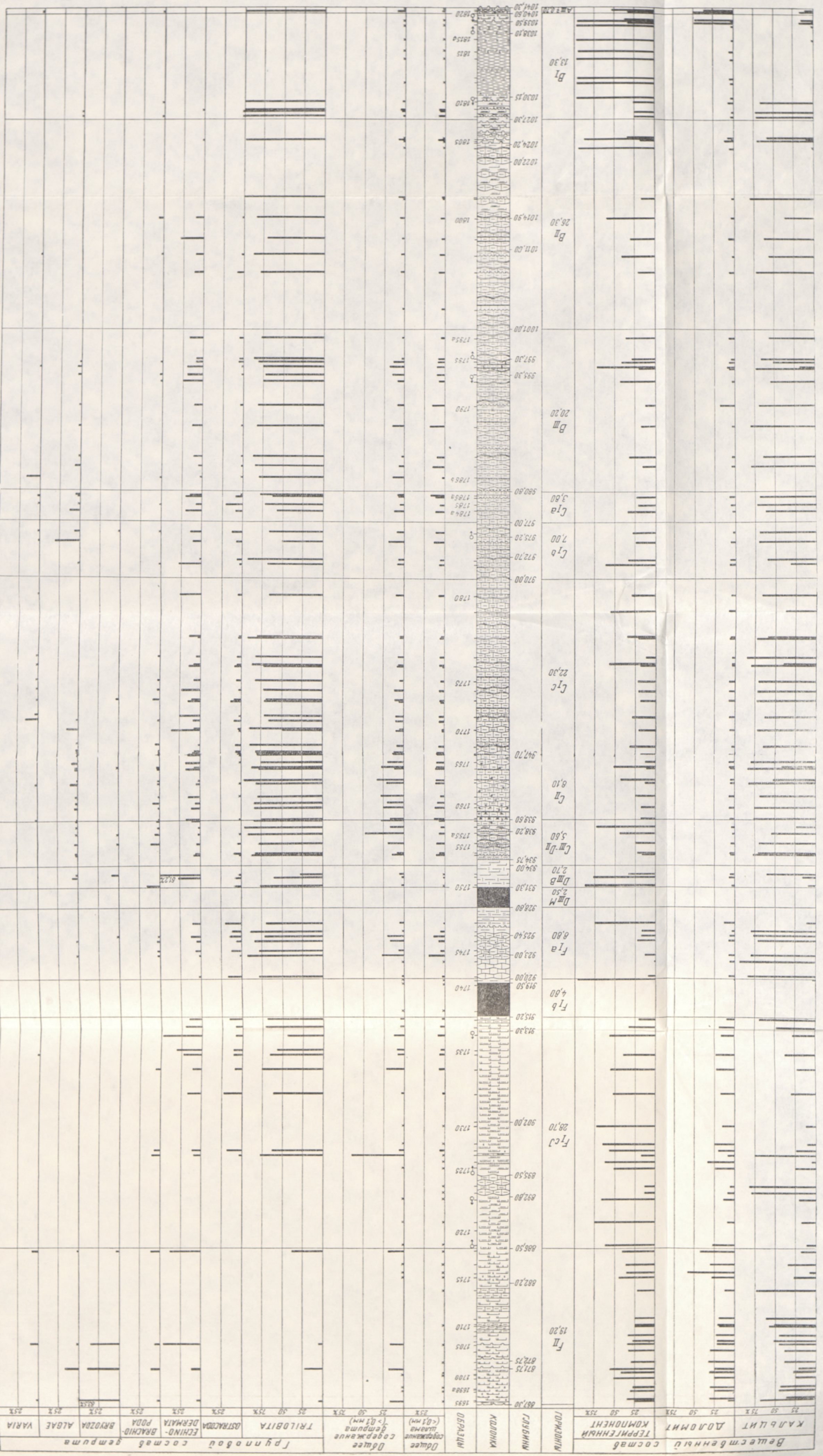


материала (в основном детритового и сгусткового), бо́льшим разнообразием группового состава детрита, присутствием водорослей н строматолитов, окатанным и несколько сортированным детритом, более ясной слоистостью (до микрослоистости), относительно частыми поверхностями перерыва, знаками ряби и трещин усыхання. На основе этого комплекса признаков можно выделить следующие этапы относительно более мелко. водного осадконакопления: 1) $\mathrm{A}_{\text {II? }}$ и низы $\mathrm{B}_{\mathrm{I}}$; 2) пограничные слои $\mathrm{B}_{\mathrm{I}}^{\prime} \mathrm{B}_{\mathrm{II}}$; 3) сероцветная часть $\mathrm{B}_{\mathrm{III}}$; 4) $\mathrm{C}_{\mathrm{I}} \mathrm{a}-\mathrm{C}_{\mathrm{I}} \mathrm{b}$; 5) $\mathrm{C}_{\mathrm{II}}-\mathrm{D}_{\mathrm{II}}$; 6) средняя

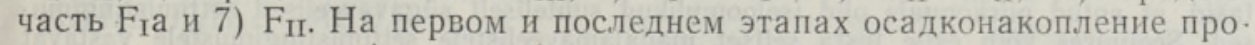
текало к тому же в более прибрежных условиях.

Присутствие на всех названных выше уровнях водорослевого детрита, а также сравнительно обильное содержание детрита со следами жизнедеятельности сверлящих водорослей дает основание предполагать (см. Маслов, 1956), что глубина бассейна в указанные перноды, вероятно, не превышала 50 м, а временами была значительно меньшей.

\section{Л И ТЕ РА Т У РА}

Вингиса ар П., Ораспыльд А., Эйнасто Р., Юргенсон Э. 1965 . Единая классификащия и легенда карбонатных пород. Таллин.

В ин ги с а а р П. 1971. Микролитологическсе исследование известняков ордовикского разреза скважины Хаапсалу. Изв. АН ЭССР, Хим. Геол., 20, № 1.

В олколаков Ф. К., Сп ринги с Т. К. 1969. Литологические особенности верхнеордовикских нефтеносных отложеннй Западной Латзии. В сб.: Вопросы региональной геологии Прибалтики и Белоруссни. Рига.

Гл аголев А. А. 1933. О геометрических методах колнчественного минералогического анализа горных пород. Тр. Ин-та прнкл. минерал., № 59, М.-Л. М а сл о-В В. П. 1937. Атлас карбонатных пород, ч. 1, Породообразующие организмы.

М а слов В. П. 1956. Ископаемые известковые водоросли СССР. Тр. Ин-та геол. наук АН СССР, вып. 160.

М яннил в Р. М. 1966. История развиткя Балтийского бассейна в ордовике. Таллин.

М янниль Р. М., Пылма Л. Я., Хин т с Л. М. 1968. Стратиграфия вируских и харьюских отложений (ордовик) Средней Прибалтики. В сб.: Стратиграфия

нижнего палеозоя Прибалтики и корреляция с другими регионами. Вильнюс.
$\mathrm{X}$ в ор ов а И. В. 1958. Атлас карбонатных пород среднего и верхнего карбона Русской платформы. $M$.

Ш в а рц Т. В., К а р п и ц к й В. Я. 1970. Нефтепоисковые работы в Западной Латвин. Тр. Ин-та геол., вып. 8 , Вильнюс.

Ш в ец о в М. С. 1958. Петрография осадочных пород. М.

C a r o z z i A. V. 1958. Micro-mechanisms of sedimentation in the epicontinental environment. J. Sediment. Petrol., 28, No. 2.

Cron oble W. R.,W a d d e 11 D. E. 1966. Petrology of Lester limestone (Desmoinesian), Carter and Love Counties, Oklahoma. Oklahoma Geol. Notes, 26, No. 6.

$\mathrm{J}$ a a n u s s c n V. 1952. Untersuchungen über die Korngrösse der ordovizischen Kalksteine, Geol. Fören. Förhandl., 74, H. 2.

$\mathrm{K}$ a hle C. F. 1965. Possible roles of clay minerals in the formation of dolomite. J. Sediment. Petrol., 35, No. 2.

Lindholm R. C. 1969. Carbonate petrology of the Onondaga limestone (Middle Devonian) New York: a case for calcisiltite, J. Sediment. Petrol., 39, No, 1

M a rtn a J. 1955. Studies on the Macrourus and Slandrom Formations I. Shell fragment frequencies of the Macrourus Formation and adjacent strata at Fjäcka, Gräsgărd and File Haidar. Geol. Fören. Förhandl., 77.

Putdy E. G. 1963. Recent calcium carbonate facies of the Great Bahama Bank, part I, Petrography and reaction groups. J. Geol., 71, No. 3.

$\mathrm{S}$ a $\mathbb{1}$ le r H. E. 1966. A detailed study of microfacies in the Mid-Viséan $\left(\mathrm{S}_{2}-\mathrm{D}_{1}\right)$ limestones near Hartington, Derbyshire, England. J. Sediment. Petrol., 36, No. 4.

$\mathrm{S}$ t a u f f e r K. W. 1962. Quantitative petrographic study of Paleozoic rocks, Caballo Mountains, New Mexico. J. Sediment. Petrol., 32, No. 3.

Sugden W. 1966. Pyrite staining of pellety debris in carbonate sediments from the Middle East and elsewhere. Geol. Mag., 103, No. 3. 


\section{POLMA}

\section{DETRIIDI KOOSTIS JA HULK BALTIKUMI ORDOVIITSIUMI BASSEINI KESKVOONDI SETETES}

(Engure puursüdamiku alusel)

Esmakordselt iseloomustatakse Baltikumi ordoviitsiumi basseini keskvööndi terrigeenkarbonaatses settekompleksis sisalduva detriidi suhtelist hulka, morfoloogiat ja leviku sea. dıspärasusi ning detriiti moodustavate fossiilirühmade esinemissagedust. Uurimised näitasid, et antud piirkonnale olid iseloomulikud suhteliselt sügavaveelised settimistingimu. sed. Seejuures võib esile tôsta seitset madalamaveelistele settimistingimustele vastavat läbilōike osa.

\section{POLMA}

\section{SKELETAL DEBRIS CONTENT AND COMPOSITION IN THE SEDIMENTS OF THE EAST BALTIC ORDOVICIAN FACIAL AXIAL BELT}

\section{(Engure boring)}

The content of skeletal debris and distribution of different debris-forming faunal groups in the Upper Tremadocian - Upper Ashgillian sequence of the Engure core (Latvian SSR.) has been studied by the point-counting method.

In the table, left of the column of the examined sequence, the chemical composition of rocks (in weight percentages), and right of the column, the total content of skeletal debris in two fractions and distribution of different debris-forming faunal groups (in volume percentages), is shown.

The average debris content in the samples analyzed is rather small $(11.4 \%)$. Fragments of trilobites prevail (average content $76 \%$ ), which represent, in places, the only group of debris-forming fauna. The following groups are echinoderms $(14.5 \%)$, ostracodes $(5-7 \%)$ and brachiopods (5-6\%). The debris formed by bryozoans, molluscs, rugose corals and algae occurs less frequently and more sporadically. The skeletal debris examined is in most cases weakly rounded and poorly oriented.

On the basis of studied features it is assumed that during the most of the Ordovician time relatively deep-water environment was prevailing in the axial belt of the East Baitic area. On that general background, seven short periods of shallow-water sedimentation may be stated. 